\title{
The psychological mechanism of Internet information processing for post- treatment evaluation: implications for healthcare system development
}

\author{
Quan-Hoang Vuong, Tam-Tri Le *, Viet-Phuong La, Minh-Hoang Nguyen * \\ Centre for Interdisciplinary Social Research, Phenikaa University, Yen Nghia Ward, Ha Dong \\ District, Hanoi 100803, Vietnam \\ * Correspondence: hoang.nguyenminh@phenikaa-uni.edu.vn; tri.letam@phenikaa-uni.edu.vn
}

August 28, 2021

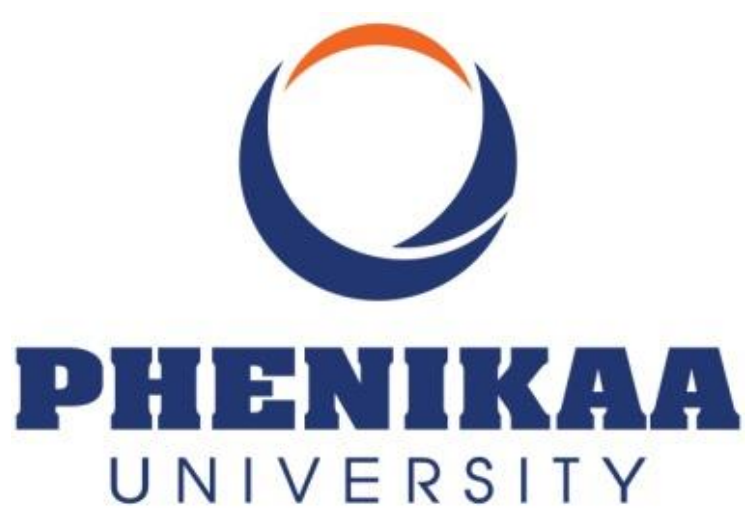

$* * * * * * * *$

\begin{abstract}
Digital healthcare has been contributing considerable merits to the public health system, especially during the Covid-19 pandemic. Within a digital healthcare system, the role of information communication through the Internet is crucial. The current study explores how patients' accessibility and trust in the Internet information influence their decisions and ex-post assessment of healthcare providers by employing the Bayesian Mindsponge Framework (BMF) on the dataset of 1,459 Vietnamese patients. We find that patients' accessibility to Internet information positively affects the perceived sufficiency of information for choosing a healthcare provider, and their trust in the information intensifies this effect. Nevertheless, being more accessible to Internet information is negatively associated with the post-treatment negative feeling about healthcare providers, and trust also moderates this effect. Moreover, patients considering professional reputation important while making a decision are more likely to regard their choices optimal, whereas patients considering services important have contradicting tendencies. Based on these findings, a concern about the risk of eroding trust toward Internet sources about healthcare information is raised. Thus, quality control and public trust-building measures need to be taken to improve communication effectiveness through the Internet and eventually facilitate the adoption of the digital health system.
\end{abstract}


Keywords: digital healthcare, healthcare quality, public communication, mindsponge mechanism, Internet information, BMF

\section{Introduction}

During the combat with the COVID-19 pandemic, digital health has played an important role in the public health system. Due to the dynamic fluctuations in demand, capacity, and even contextual aspects of health care attributable to the COVID-19 pandemic, the conventional faceto-face care model has to be reconfigured. Many countries, therefore, have incorporated digital technology in their new healthcare model for improving efficiency, reducing transmission risks, and enhancing flexibility while providing care (Gunasekeran et al., 2021). Integrating digital technology into healthcare systems is also essential among low- and middle-income countries (LMICs). It is one of the non-pharmaceutical interventions that help to minimize the adverse impacts of the COVID-19 pandemic (Chowdhury et al., 2020; Walker et al., 2020). Mitgang et al. (2021) suggest that LMICs' healthcare systems can be markedly improved by employing information and communication technologies (ICTs) to enhance direct communication with the public, develop scale-proven and innovative service delivery models, and empower the frontlines.

Digital health, which was first introduced by Frank (2000), provides consumers five fundamental functions: 1) information dissemination, 2) informed decision-making support, 3) health promotion, 4) a medium to exchange information and support, 5) self-care improvement and demand management. Even though the field rapidly expands to cover other scientific concepts and technologies, like artificial intelligence, analytics, mobile applications, telemedicine, etc. (Mathews et al., 2019), dissemination and communication of information through the Internet still play crucial roles in the modern digital health system, and even digital health ecosystem (Serbanati et al., 2011).

The Internet is a useful source of information for various health issues, such as disease prevention, treatment to recovery, reduced psychological stress, increased satisfaction, etc. (Galarce et al., 2011). Dickerson et al. (2011) find that men with cancer seek information about disease and treatments from the Internet for decision making, organizing information, and navigating through the health system politics and power. Online health information has a mediation effect on the association between social support and healthy eating intentions (McKinley \& Wright, 2014). Apart from disease treatment and behavior changing, the Internet is also a channel for acquiring healthcare reform information (Thompson et al., 2012). As Internet information-seeking behaviors increasingly contribute to people's health-related decisions, their behavioral outcomes are also altered accordingly. A study on Chinese patients suggests that the quality and source of internet-based information positively influences patient compliance, which improves treatment effectiveness (Lu et al., 2018). Furthermore, trust in healthcare providers, online health information, and Internet use significantly predict the intention to discuss health with their providers (Hong, 2008).

Healthcare information is a crucial factor in consumer-driven healthcare models (Harris et al., 2008). Quality information can help improve quality and minimize healthcare costs by empowering patients to take part in their healthcare and improving their informed decisionmaking in choosing healthcare providers (Cable.co.uk, 2004; Rains, 2007). Thanks to the rapid 
development of ICTs, the Internet has become increasingly available and become one of the trusted information sources on care providers, apart from mass media, professional experts, and family members and friends (Harris et al., 2008; Rains, 2007; Tu \& Lauer, 2008). According to Lemire et al. (2008), the use of the Internet as a preferred source of information is associated with five factors: perceived usefulness, trust in the information, opinions of health professionals, the reporting media, and personal health concerns. Despite the mounting literature regarding the effects of internet-based information on multiple health-related information, little is known about the relationship between the psychological process of online information and patients' selection and post-treatment evaluation of healthcare providers. The received information from the Internet might be both good and bad (Tonsaker et al., 2014). However, no matter how it is, if the information is used to decide a healthcare provider, it might affect the post-treatment evaluation of patients. Thus, a good evaluation of decisions based on Internet information is expected to increase perceived usefulness and trust into the information sources, and vice versa, and eventually influence patients' information-seeking behaviors in the future (Lemire et al., 2008; Sheng \& Simpson, 2015).

Vietnam - one of LMICs with more than 96 million population - has been heavily affected by the recent outbreaks despite the successful containment in early COVID-19 waves. Since July 1 , 2021, the total of COVID-19 infected cases in Vietnam has substantially by about 30 times (from 17,727 to 550,996 cases) after less than three months (until September 7, 2021) (Ritchie et al., 2020). The devastating situation is attributable to a combination of factors, such as the high transmissibility of the Delta variant, slow vaccine rollout, etc. Inadequate development of the digital health system is also one of the significant contributors to the outbreak (Bui et al., 2021). However, Vietnam has great potential to capitalize on the Internet for communicating health and healthcare information with patients. Approximately $70 \%$ of the population gains access to the Internet and the lowest price of Internet services in South East Asia (Cable.co.uk, 2004; The World Bank, 2020). Bui et al. (2021) stipulate that the inadequacy results from supply-side problems, such as the lack of strong governance, infrastructure, and staff capability for digital health development and deployment. Besides, the challenges of digital health can also be derived from societal factors (e.g. low public acceptance, medical misinformation dissemination on the Internet, unequal accessibility towards digital services, etc.) (Cummins \& Schuller, 2020; Lennon et al., 2017).

Therefore, understanding the patients' psychological process of Internet information for selection and ex-post evaluation of healthcare providers is anticipated to provide useful insights for developing countries ambitious to develop a digital healthcare system, like Vietnam. According to Mindsponge information processing mechanism (Q.-H. Vuong \& N. K. Napier, 2015), perceived information accessibility and trust are two fundamental elements of an individual's psychological process. The current studies aim to examine the following two research questions using the Bayesian Mindsponge Framework (BMF) - the combination of the Mindsponge mechanism and Bayesian analysis (Nguyen et al., 2021). A detailed explanation of the theoretical foundation based on BMF will be presented in the Model Construction subsection. 
1. How do accessibility and trust in Internet information influence patients' decision of choosing healthcare providers?

2. How do accessibility and trust in Internet information influence patients' posttreatment evaluation of healthcare providers?

\section{Methodology}

2.1. Materials

The current study employed the dataset of 1459 patients visiting 30 hospitals across North Vietnam. The data resulted from face-to-face interviews conducted by a six-member data team from the fourth quarter of 2015 to the beginning of 2016. The survey collection was designed and implemented by Hanoi-based Vuong \& Associates, with the ethical standards maintained by the institutional regulation and decision, numbered V\&A/15\#1 dated October 19, 2015. The team members were carefully instructed with written rules and standards of research ethics. Respondents were also asked to accept a written consent before participating in the survey.

Among 1459 participants, more than half were female patients (64.56\%), while male patients constituted $35.57 \%$. Their average age was approximately 32. The proportion of non-poor patients $(78.96 \%)$ was almost four times higher than poor patients $(21.04 \%)$. A majority of patients were residing in urban areas $(73.06 \%)$, while the rest came from rural $(22.62 \%)$ or remote areas $(4.32 \%)$.

Seven variables were retrieved from the dataset for performing Bayesian analysis. Most of them are binary variables; only the patients' perceived accessibility to Internet information is represented by a numerical variable (Internet). Table 1 shows seven variables as well as their detailed description and how they were coded. Sufficiency and Posttreatment are two outcome variables, whereas the other five variables are predictor variables.

Table 1: Variables' detailed description

\begin{tabular}{|c|c|c|c|}
\hline Name & Variable & Data type & Description \\
\hline $\begin{array}{l}\text { Perceived } \\
\text { sufficiency of the } \\
\text { information }\end{array}$ & Sufficiency & Binary & $\begin{array}{l}\text { Patients' subjective assessment of information } \\
\text { sufficiency for choosing a healthcare provider. } \\
\text { 'Sufficient' was coded as } 1 \text {, 'Not sufficient' as } \\
0 \text {. }\end{array}$ \\
\hline $\begin{array}{c}\text { Post-treatment } \\
\text { assessment }\end{array}$ & Posttreatment & Binary & $\begin{array}{l}\text { Patients' post-treatment assessment of whether } \\
\text { a patient's choice was the best available. } \\
\text { 'Optimal' was coded as } 1 \text {, 'Not optimal' as } 0 \text {. }\end{array}$ \\
\hline $\begin{array}{l}\text { Accessibility of } \\
\text { Internet } \\
\text { information }\end{array}$ & Internet & Numerical & $\begin{array}{l}\text { Patients' perceived accessibility to information } \\
\text { related to the healthcare provider on the } \\
\text { Internet. 'Limited and difficult' was coded as } 1 \text {, } \\
\text { 'Somewhat limited but still available' as } 2 \text {, } \\
\text { 'Easy and convenient' as } 3 \text {. }\end{array}$ \\
\hline $\begin{array}{l}\text { Trust towards } \\
\text { Internet } \\
\text { information }\end{array}$ & Internet_Trust & Binary & $\begin{array}{l}\text { Patients' trust towards the information related } \\
\text { to the healthcare provider on the Internet. } \\
\text { 'Believe' is coded as } 1 \text {, 'Only for reference } \\
\text { when needed' as } 0 \text {. }\end{array}$ \\
\hline
\end{tabular}




\begin{tabular}{|c|c|c|l|}
\hline $\begin{array}{c}\text { Importance of } \\
\text { provider's } \\
\text { services }\end{array}$ & Services & Binary & $\begin{array}{l}\text { Patients' perceived importance of provider's } \\
\text { services in the determination of healthcare } \\
\text { provider. 'Decisive' is coded as 1, 'Indecisive' } \\
\text { as 0. }\end{array}$ \\
\hline $\begin{array}{c}\text { Importance of } \\
\text { professional } \\
\text { reputation }\end{array}$ & Reputation & Binary & $\begin{array}{l}\text { Patients' perceived importance of provider's } \\
\text { reputation in the determination of healthcare } \\
\text { provider. 'Decisive' is coded as 1, 'Indecisive' } \\
\text { is coded as 0. }\end{array}$ \\
\hline $\begin{array}{c}\text { Importance of } \\
\text { provider's cost }\end{array}$ & Cost & Binary & $\begin{array}{l}\text { Patients' perceived importance of provider's } \\
\text { cost in the determination of healthcare } \\
\text { provider. 'Decisive' is coded as 1, 'Indecisive' } \\
\text { as 0. }\end{array}$ \\
\hline
\end{tabular}

\section{2. $\quad$ Model construction}

The present investigation employs the BMF, also known as the Bayesian Mindsponge analytical approach (Nguyen \& Le, 2021), to study patients' psychological mechanisms of Internet information processing for selecting and evaluating healthcare providers. The Mindsponge information processing framework (Q. H. Vuong \& N. K. Napier, 2015) was used as the theoretical foundation to construct models, while Bayesian analysis was used to explore the constructed models statistically. BMF, proposed by Nguyen et al. (2021), has been shown to effectively examine the underlying psychological mechanisms of behaviors and attitudes (Vuong et al., 2021a; Vuong et al., 2021b)

Mindsponge mechanism demonstrates how the mind receives and filters information, accepts or rejects values, and updates itself in the process. Information accessibility and favorable evaluation of the information are two fundamental conditions for a new piece of information to be accepted into the mindset. Regarding the first condition, this requires both objective availability and perceived accessibility of the information. The information needs to exist, be reachable and considered reachable for being received by the mind. Regarding the second condition, when the information is received, it has to go through the multi-filtering system, consisting of many cost-benefit judgments based on related information gathered from the environment and references of existing trusted values from the mindset (formerly accepted values). Suppose the total perceived benefit of the information's value is greater than its perceived cost. In that case, it will be accepted into the mindset and becomes a new trusted value, and vice versa (rejection).

Along the Mindsponge process, trust (or "trust guard") has a particularly important role. Trust is a special reference from the mindset based on formerly accepted values (or information) to justify the certainty or uncertainty of the information. Thus, it can greatly influence the costbenefit judgments, which help speed up the evaluation process. Normally, trust (or distrust) is applied to a source of information or a group of information-carrying certain similar properties. By doing so, the mind can save time and energy by quickly accepting or discarding information belonging to the same source or group without conducting the whole evaluation process again for each value. This natural trust mechanism has advantages (e.g., overall efficiency to make a 
decision) and disadvantages (e.g., lack of consideration of inaccurate and fake information). It should be noted that the Mindsponge process, just like a human, has a feedback loop, so individuals' trust and cost-benefit judgments can be changed if their core values in the mindset are replaced. The psychological process of Internet information is visualized in Figure 1.

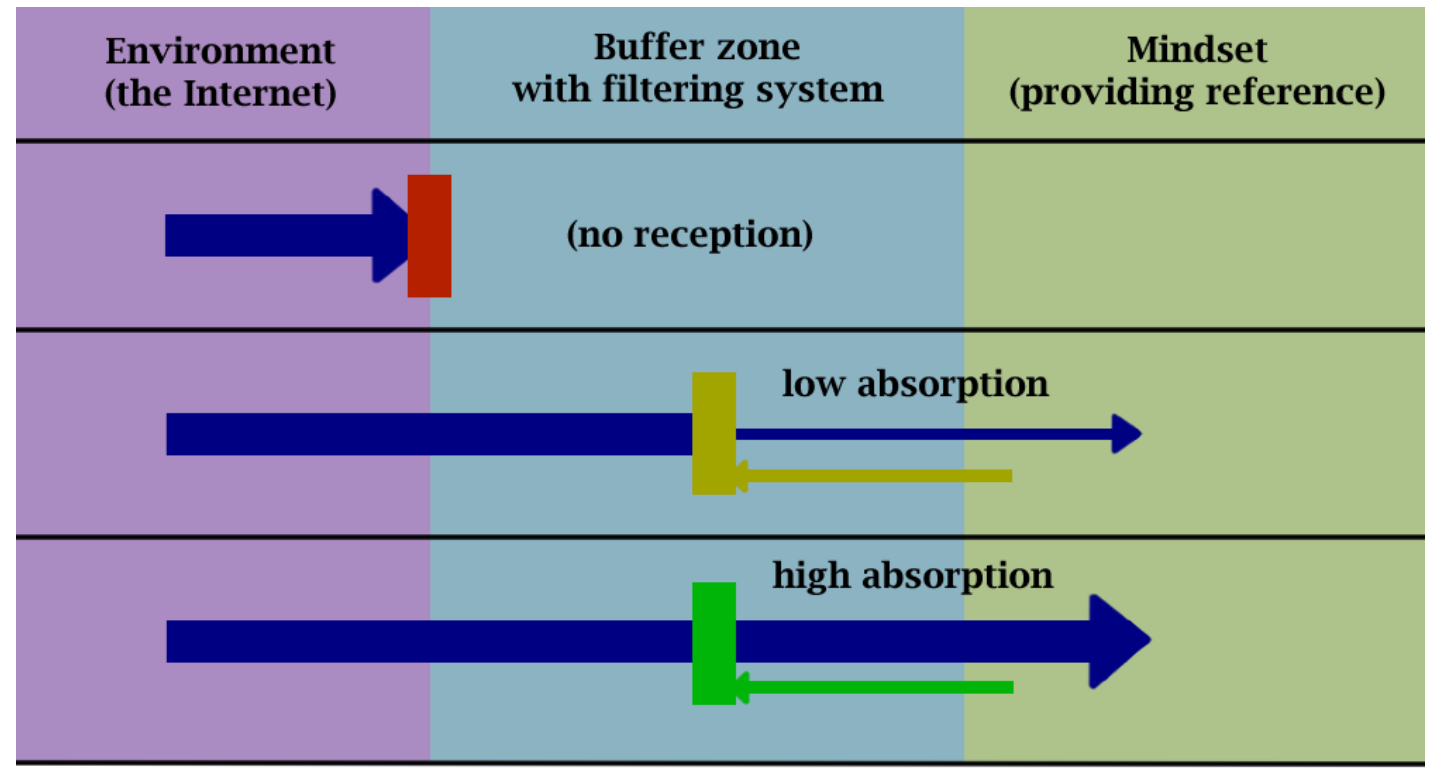

Information flow

Inaccessibility
Filtering without trust

Filtering with trust

Figure 1: Psychological mechanism of Internet information processing

Based on the theoretical foundation briefly presented above, we begin assuming that a patient needs a certain amount of information to make a decision, so the accessibility to Internet information will positively influence the patient's perceived sufficiency of information to choose a provider. Such influence will be facilitated by the patient's level of trust towards the information: more trust in the information means easier reception of that information into the mindset. Hence, Model 1 is proposed to test our first hypothesis:

\section{Model 1: Sufficiency $\sim \alpha+$ Internet + Internet $*$ Internet_Trust}

If the associations in Model 1 are validated, we continue with Model 2; otherwise, the analysis will be stopped. The patients made a choice based on the information absorbed into the mindset, including Internet and non-Internet information. Thus, their ex-post evaluation of the treatment would be based on comparing three types of information: formerly collected information (internet and non-Internet information) and information from real experience. Thus, we assume that accessibility and trust towards Internet information will influence the ex-post evaluation of whether the selected healthcare provider is optimal or not. Model 2 can be presented as follows:

Model 2: Posttreatment $\sim \alpha+$ Internet + Internet $*$ Internet_Trust 
Next, we constructed Model 3 by incorporating three aspects that might fluence the posttreatment evaluation among patients: cost, professional reputation, and services. There are two reasons for doing so. First, adding more variables into the model will help validate the robustness of Model 2's findings. If the effects of accessibility and trust towards Internet information remain robust, they can be deemed reliable. More details of the validation will be explained in the following subsection. Model 3 also provides insights into the associations of post-treatment evaluation with the importance of cost, professional reputation, and services in selecting providers, which helps suggest issues that can be improved upon while disseminating information. Combining all parameters, we derive the following model:

Model 3: Posttreatment $\sim \alpha+$ Internet + Internet $*$ Internet_Trust + Cost + Reputation + Services

\subsection{Method and validation}

We employed Bayesian analysis with the Markov Chain Monte Carlo technique in the present study for several reasons. Firstly, Bayesian inference treats all parameters (including unknown ones) as probabilities, which helps avoid the pitfall of p-value over-dependence that leads to the current reproducibility crisis in social sciences and especially psychology (Baker, 2015; Open Science Collaboration, 2015). Secondly, the properties of Bayesian inference are suitable for the explanatory research design of the present study, which examines the psychological process of receiving and filtering information for choosing a healthcare provider and evaluating the choice after treatment. With all parameters treated probabilistically, Bayesian analysis helps us consider the influence of other unknown factors while upholding the law of parsimony (Csilléry et al., 2010). Thirdly, the Markov Chain Monte Carlo technique can generate a large set of parameters' iterative samples through stochastic processes of Markov chains, which provides sufficient sample size for fitting the complex models, including nonlinear relationships (Kerkhoff \& Nussbeck, 2019).

A four-pronged validation strategy was employed to validate the simulated posterior results. Initially, we checked the model's goodness-of-fit using the Pareto smoothed importancesampling leave-one-out cross-validation (PSIS-LOO) strategy (Vehtari et al., 2017). If all $k$ values shown on the PSIS diagnostic plot are lower than 0.5, the model can be deemed acceptable without under- nor over-fit. In the second step, we examined the Markov chain central limit theorem, which assumes that iterative samples in a Markov chain are independent (or not convergent). The effective sample size (n_eff) and Gelman shrink value (Rhat) as well as the trace plot, Gelman plot, and autocorrelation plot were employed to diagnose the convergence.

Although the prior distributions are assumed to be "uninformative" to minimize the subjective influence on the simulated results, we also performed the "prior-tweaking" technique to check the simulated results' robustness. In particular, we reran the analysis using distinct prior distributions (demonstrating our belief and disbelief on the acquired results) of a parameter. If the simulated results only slightly change, the findings can be considered robust. Finally, we inserted additional variables into Model 2, creating Model 3 for robustness validation. If the associations of accessibility and trust towards Internet information with the post-treatment evaluation in Model 3 are not subject to change, the findings will be validated. 
The Bayesian analysis was conducted using the bayesvl R package due to several advantages: i) being an open program, ii) having good visualization power, and iii) supporting the transparent operation (Vuong et al., 2020). The data and codes utilized for all statistical analyses and result presentations are available in the following repository: https://osf.io/9ukwg/.

\section{Results}

Out of 1459 patients, $31.53 \%$ assessed their treatment choices were optimal, while $46.40 \%$ perceived that they had had sufficient information to make good decisions. Regarding Internet information, most of the patients $(41.95 \%)$ said that Internet information accessibility was easy and convenient. Half of the patients $(49.76 \%)$ believed in the Internet information, whereas the rest only used Internet information as a reference when needed.

\subsection{Model 1: Psychological process of perceived sufficiency}

The first model investigated the effects of accessibility and trust towards Internet information on the perceived sufficiency of information to make a good choice of healthcare provider. Figure 2 demonstrates Model 1's logical network.

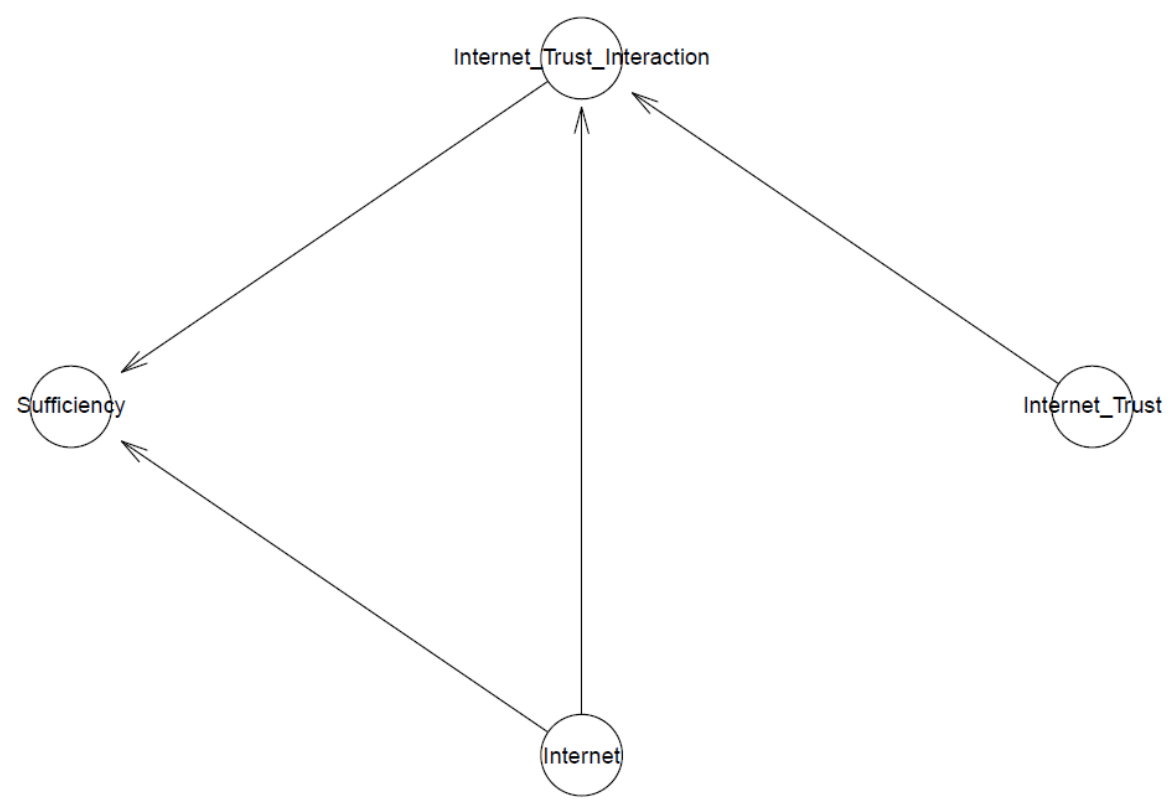

Figure 2: Model 1's logical network

The model was first validated using the PSIS diagnostic plot shown in Figure 3. All the $k$ values are below 0.5 , which indicates the model's high goodness-of-fit with the data. 


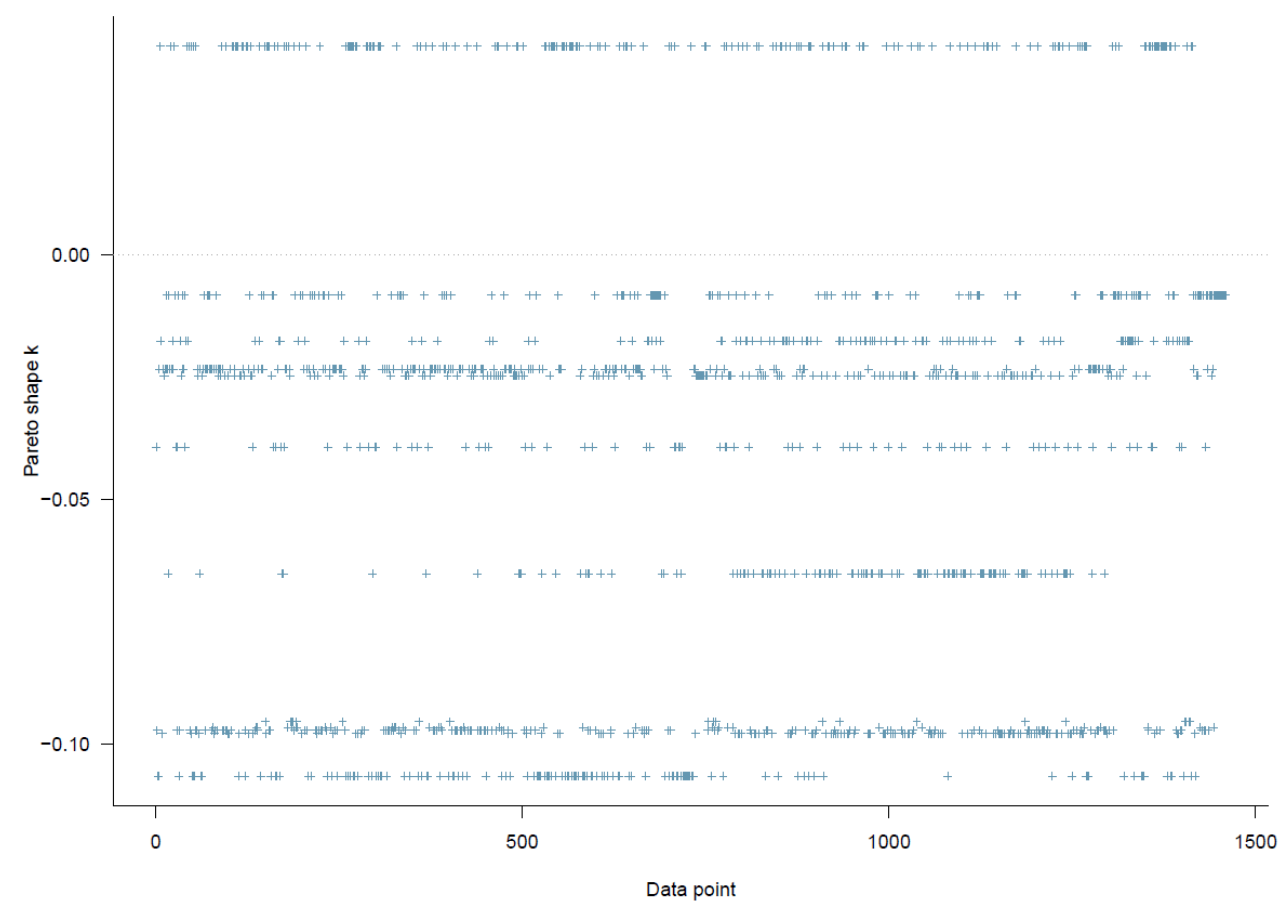

Figure 3: Model 1's PSIS diagnostic plot

The posterior coefficients' Markov chains can be deemed convergent as their n_eff values are larger than 1,000 and Rhat values are equal to 1 (see Table 2). The convergence is visually validated by the "healthy" Markov chains presented in the trace plots: good-mixing and stationary (see Figure 4). In the Gelman plots, the shrink factors drop rapidly to 1 (see Figure S1); the autocorrelation plots imply a substantial decline of autocorrelation levels after a certain number of lags (see Figure S2). These signals suggest that the Markov chains are wellconvergent, and thus the central limit theorem is held in Model 1's simulation.

Table 2: Model 1's simulated posteriors

\begin{tabular}{|c|c|c|c|c|c|c|c|c|}
\hline \multirow{2}{*}{ Parameters } & \multicolumn{2}{|c|}{$\begin{array}{c}\text { Uninformative } \\
\text { prior }\end{array}$} & $\begin{array}{c}\text { Prior-tweaking } \\
\text { (belief on } \\
\text { effect) }\end{array}$ & $\begin{array}{c}\text { Prior-tweaking } \\
\text { (disbelief on } \\
\text { effect) }\end{array}$ & n_eff* & Rhat* \\
\cline { 2 - 9 } & Mean & SD & Mean & SD & Mean & SD & & \\
\hline Constant & -0.69 & 0.16 & -0.68 & 0.16 & -0.69 & 0.16 & 4691 & 1 \\
\hline Internet & 0.18 & 0.08 & 0.17 & 0.08 & 0.18 & 0.08 & 4312 & 1 \\
\hline Internet*Internet_Trust & 0.12 & 0.05 & 0.13 & 0.05 & 0.12 & 0.05 & 5021 & 1 \\
\hline \multirow{2}{*}{$n$ n_eff and Rhat values presented in the tables are the effective sample sizes and Gelman values } \\
taken from the simulated results using uninformative prior.
\end{tabular}

As can be seen in Table 2, accessibility to Internet information is positively associated with the perceived sufficiency of information for choosing a healthcare provider $\left(\pi_{\text {Internet }}=0.18\right.$ and $\left.\sigma_{\text {Internet }}=0.08\right)$. The effect of accessibility to Internet information is also intensified by the patient's trust $\left(\pi_{\text {Internet } * \text { Internet_Trust }}=0.12\right.$ and 
$\left.\sigma_{\text {Internet*Internet_Trust }}=0.05\right)$. In other words, the effect of accessibility to Internet information on perceived information sufficiency is stronger among patients trusting the Internet data than among those who do not. The positive effects of accessibility and trust towards Internet information simulated based on Model 1 are highly reliable as the coefficients' probability distributions are located entirely on the positive side of the xaxis (see Figure 4).

To validate the simulated results, we performed the prior-tweaking technique on Internet*Internet_Trust using two prior distributions: belief on effect and disbelief on effect. The prior demonstrating our belief that the moderation effect of Internet_Trust is positive (belief on effect) was set using a normal distribution with the mean being 0.5 and standard deviation being 0.3. In contrast, a prior demonstrating our disbelief that there is a moderation effect of Internet_Trust (disbelief on effect) was set using a normal distribution with the mean being 0 and standard deviation being 0.3 . The simulated results using priors demonstrating belief and disbelief on the effect of Internet_Trust remain almost similar with the generated results employing uninformative priors (see Table 2). This outcome highlights the model's high resistance to initial changes of priors; in other words, the model is robust.

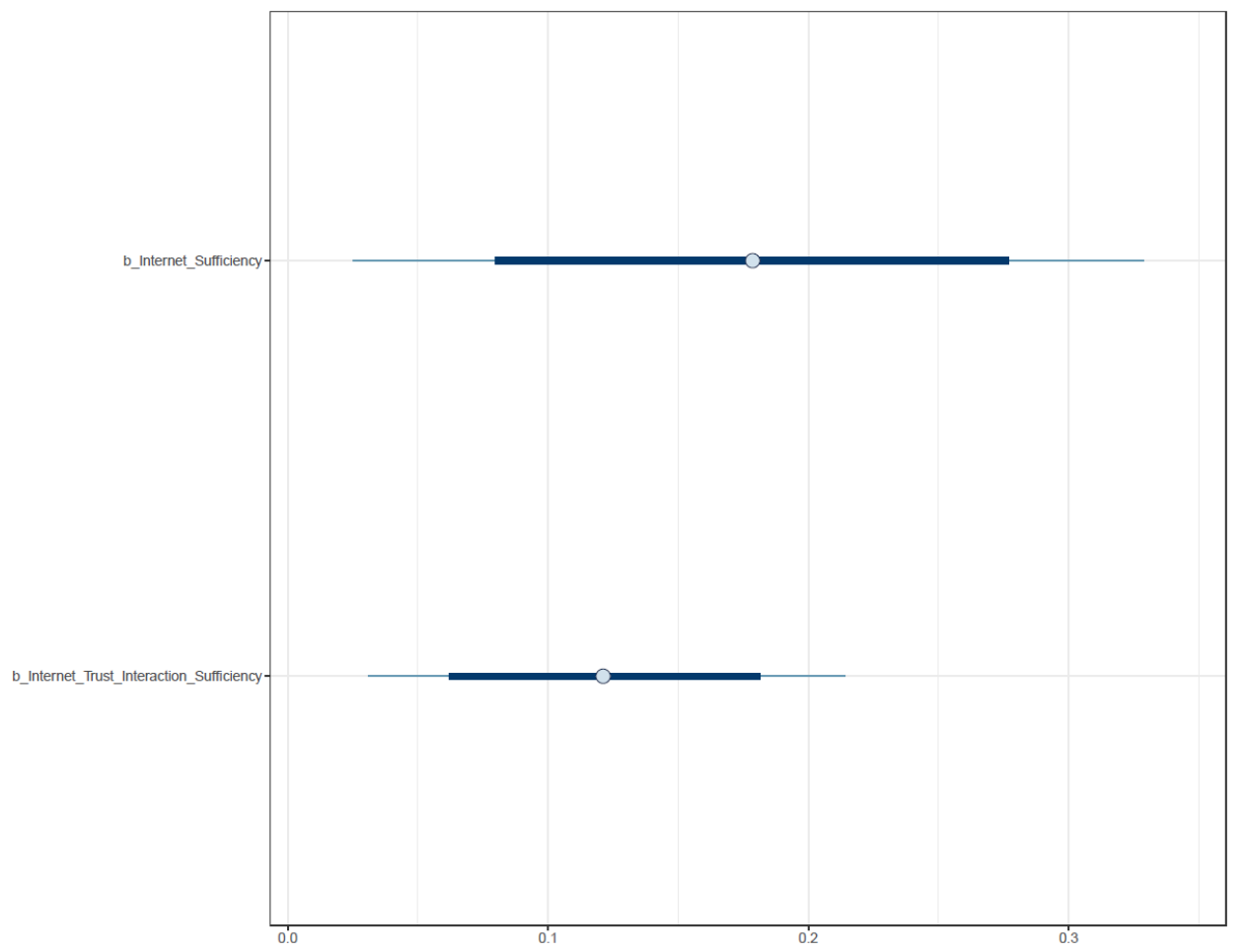

Figure 4: Distributions of Model 1's posterior coefficients on an interval plot

\section{2. $\quad$ Model 2: Psychological process of post-treatment evaluation}

Since the effects of accessibility and trust towards Internet information on the perceived information for decision making, we continued with the second model, which examines how 
patients' accessibility and trust towards Internet information influence the ex-post evaluation. Model 2's logical network can be visualized in Figure 5.

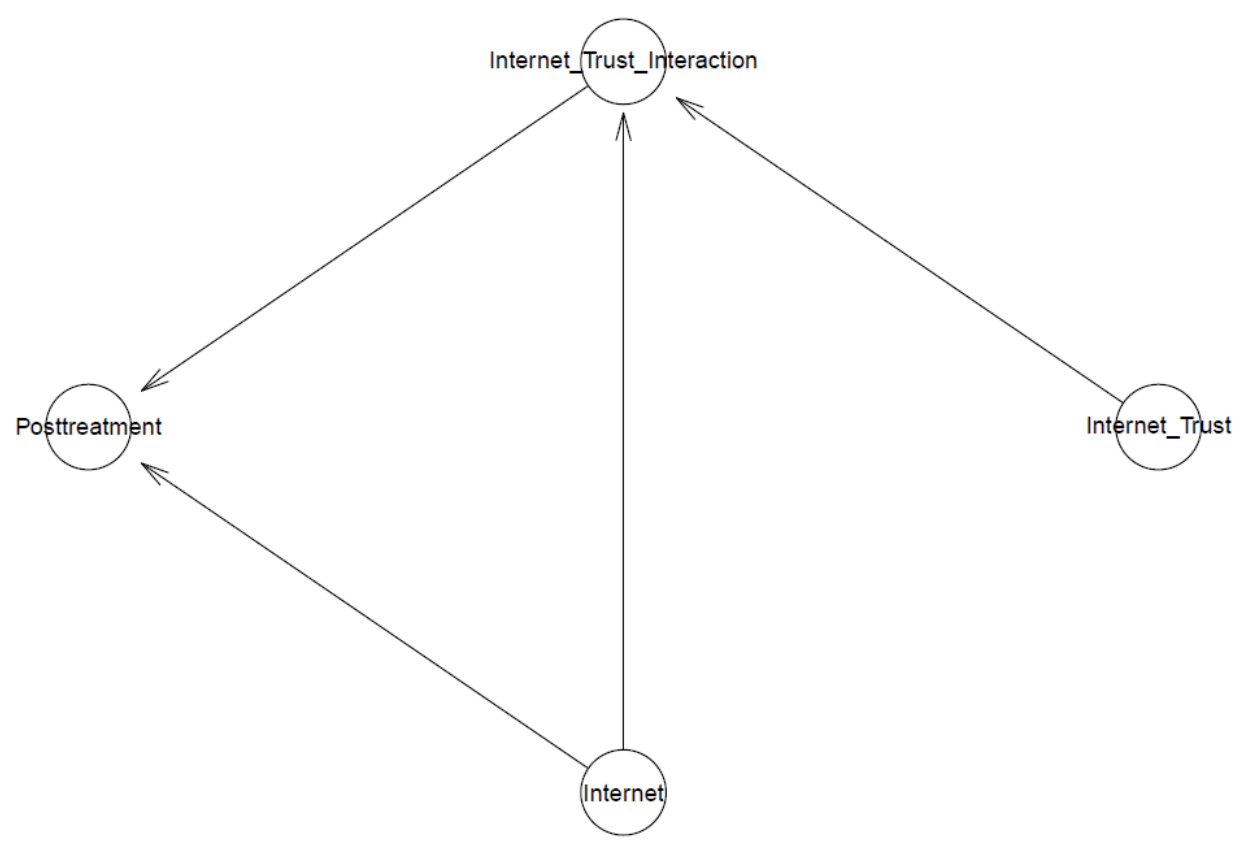

Figure 5: Model 2's logical network

Model 2 is well-fitted with the data as all $k$ values shown in the PSIS diagnostic plot are lower than 0.5 (see Figure 6).

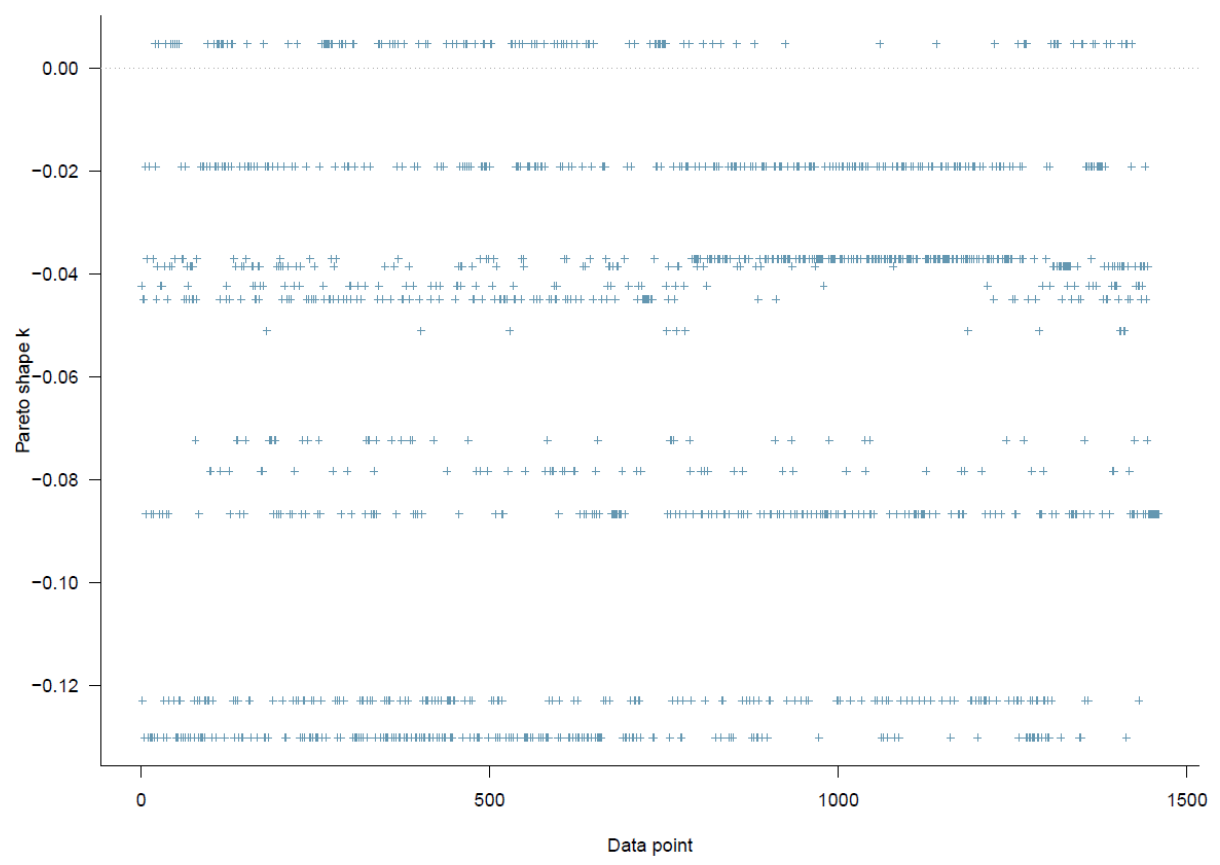

Figure 6: Model 2's PSIS diagnostic plot 
The convergence diagnostic statistics of simulated posteriors show that all parameters' Markov chains are well-convergent. Specifically, n_eff values are larger than 1000, and Rhat values are equal to 1 . The model convergence is confirmed by the well-mixed Markov chains in the trace plots (see Figure 7) and the rapid declines of shrink factors and autocorrelation levels in Gelman and autocorrelation plots, respectively (see Figures S3 and S4).
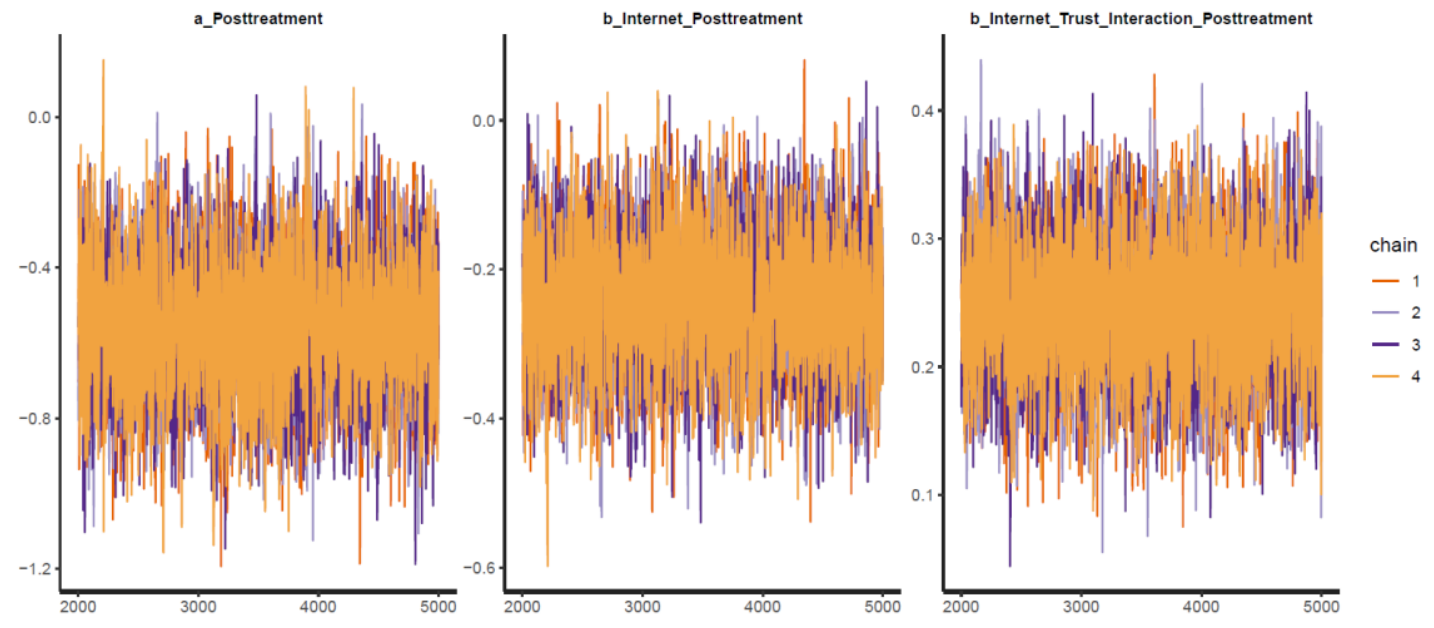

Figure 7: Model 2's trace plots

Table 3: Model 2's simulated posteriors

\begin{tabular}{|c|c|c|c|c|c|c|c|c|}
\hline \multirow[t]{2}{*}{ Parameters } & \multicolumn{2}{|c|}{$\begin{array}{l}\text { Uninformative } \\
\text { prior }\end{array}$} & \multicolumn{2}{|c|}{$\begin{array}{l}\text { Prior-tweaking } \\
\text { (belief on } \\
\text { effect) }\end{array}$} & \multicolumn{2}{|c|}{$\begin{array}{l}\text { Prior-tweaking } \\
\text { (disbelief on } \\
\text { effect) }\end{array}$} & \multirow[t]{2}{*}{ n_eff* } & \multirow[t]{2}{*}{ Rhat* } \\
\hline & Mean & SD & Mean & SD & Mean & SD & & \\
\hline Constant & -0.56 & 0.17 & -0.55 & 0.17 & -0.56 & 0.17 & 4021 & 1 \\
\hline Internet & -0.24 & 0.09 & -0.25 & 0.09 & -0.24 & 0.09 & 4038 & 1 \\
\hline Internet*Internet_Trust & 0.24 & 0.05 & 0.25 & 0.05 & 0.24 & 0.05 & 4623 & 1 \\
\hline
\end{tabular}

It is found that the accessibility to Internet information is negatively associated with the ex-post evaluation of provider choice $\left(\pi_{\text {Internet }}=-0.24\right.$ and $\left.\sigma_{\text {Internet }}=0.09\right)$. Nonetheless, patients' trust towards the Internet information negates the negative effect of accessibility to Internet information on the evaluation $\left(\pi_{\text {Internet } * \text { Internet_Trust }}=0.24\right.$ and $\left.\sigma_{\text {Internet } * \text { Internet_Trust }}=0.05\right)$. The probability distributions of Model 2's coefficients are illustrated in Figure 8. The distribution of the Internet lies mostly on the negative side. In contrast, the distribution of Internet*Internet_Trust lies entirely on the positive side (see Figure 8), so the effect of Internet and moderation effect of Internet_Trust can be deemed reliable. Applying the same tweaking technique on the prior distribution of Internet*Internet_Trust, we also obtained results independent of initial prior modification (see Table 3), which implies the robustness of Model 2. 


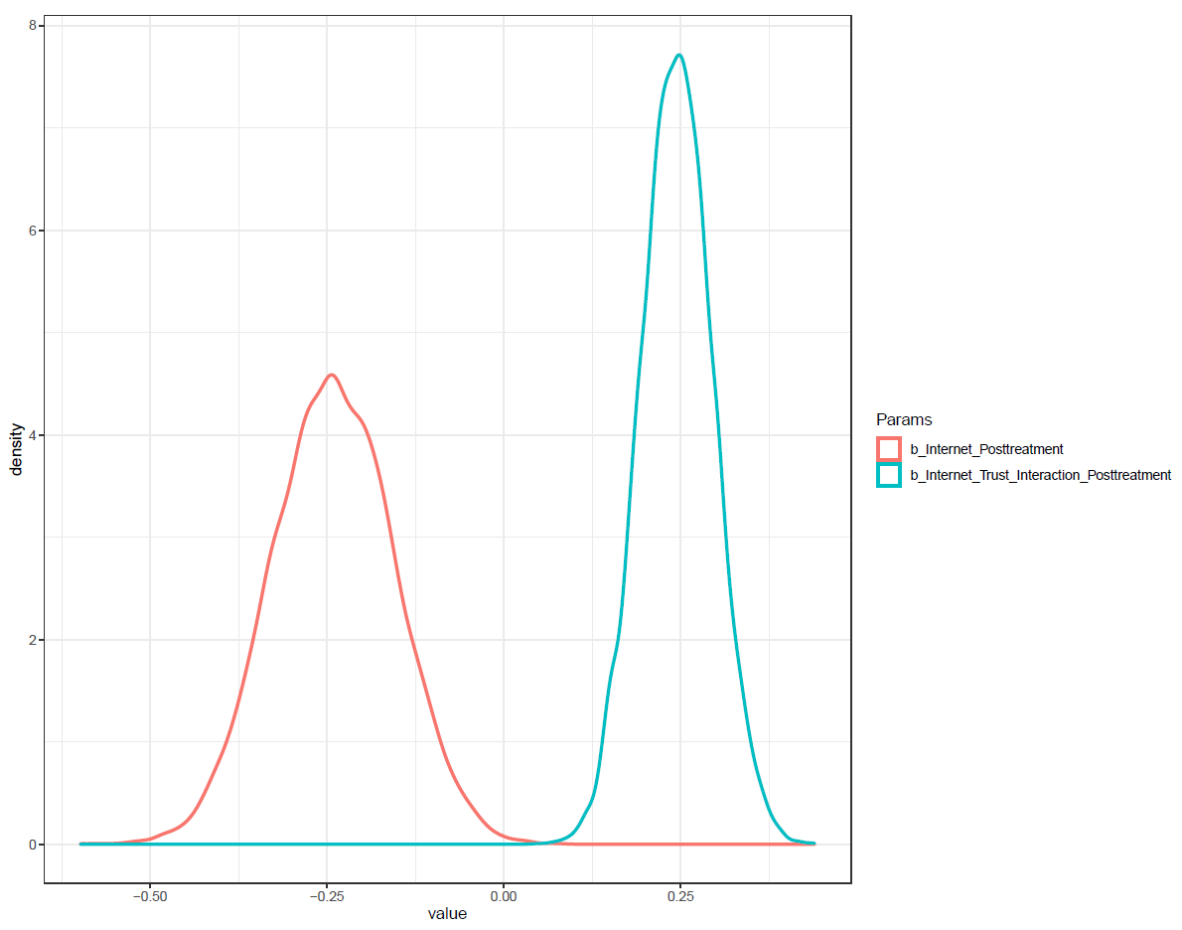

Figure 8: Distributions of Model 2's posterior coefficients on a density plot

\section{3. $\quad$ Model 3: Robustness check and model comparison}

Finally, we constructed Model 3 by incorporating Cost, Reputation, and Services into Model 2 to check the robustness of Model 2's results. Model 3's logical network is illustrated in Figure 9.

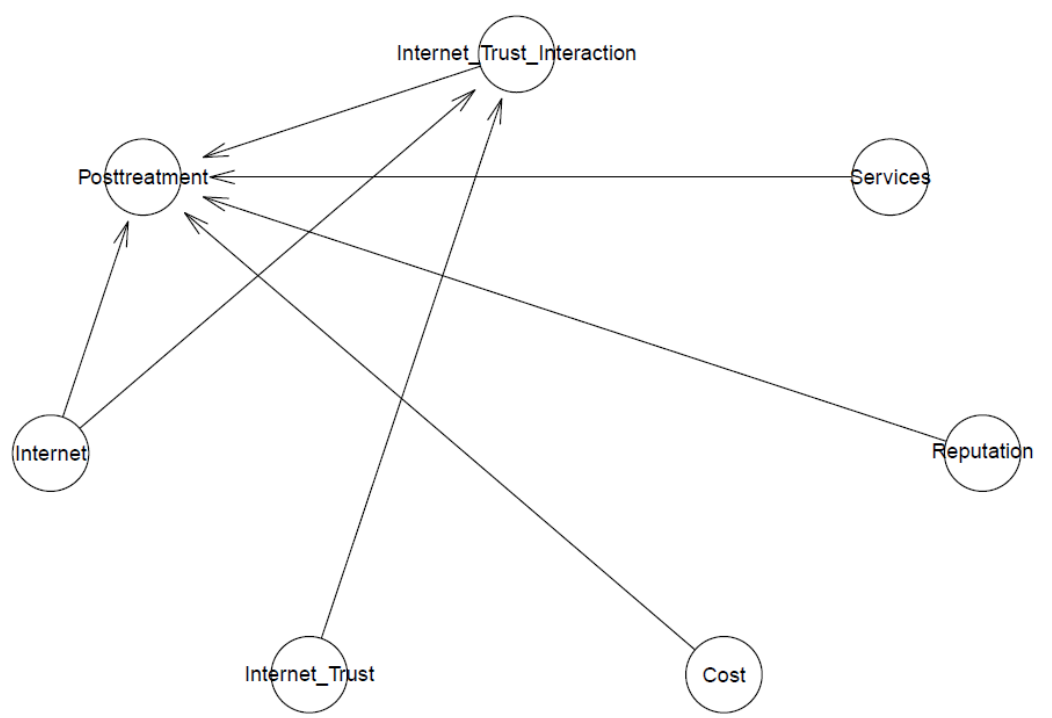

Figure 9: Model 3's logical network

Despite adding more variables into the model, the PSIS-LOO test still shows that the model is not over-fit; Figure 10 stipulates that all $k$-values are below 0.5 . 


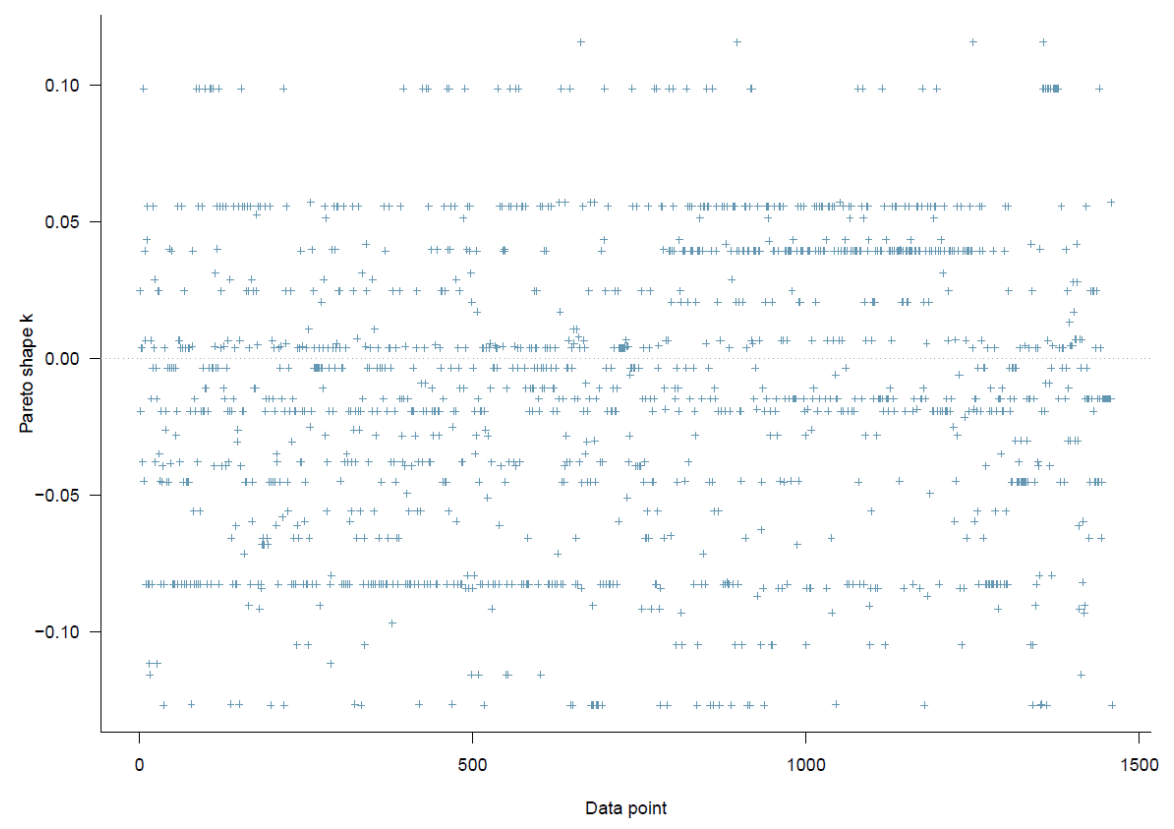

Figure 10: Model 3's PSIS diagnostic plot

All the coefficients' effective sample sizes obtain relatively large numbers of independent iterations, and Gelman values equal 1 (see Table 4). These are good signals of Model 3's Markov chain convergence. The trace plots (see Figure 11), Gelman plots (see Figure S5), and autocorrelation plots (see Figure S6) again validate the convergence signals.
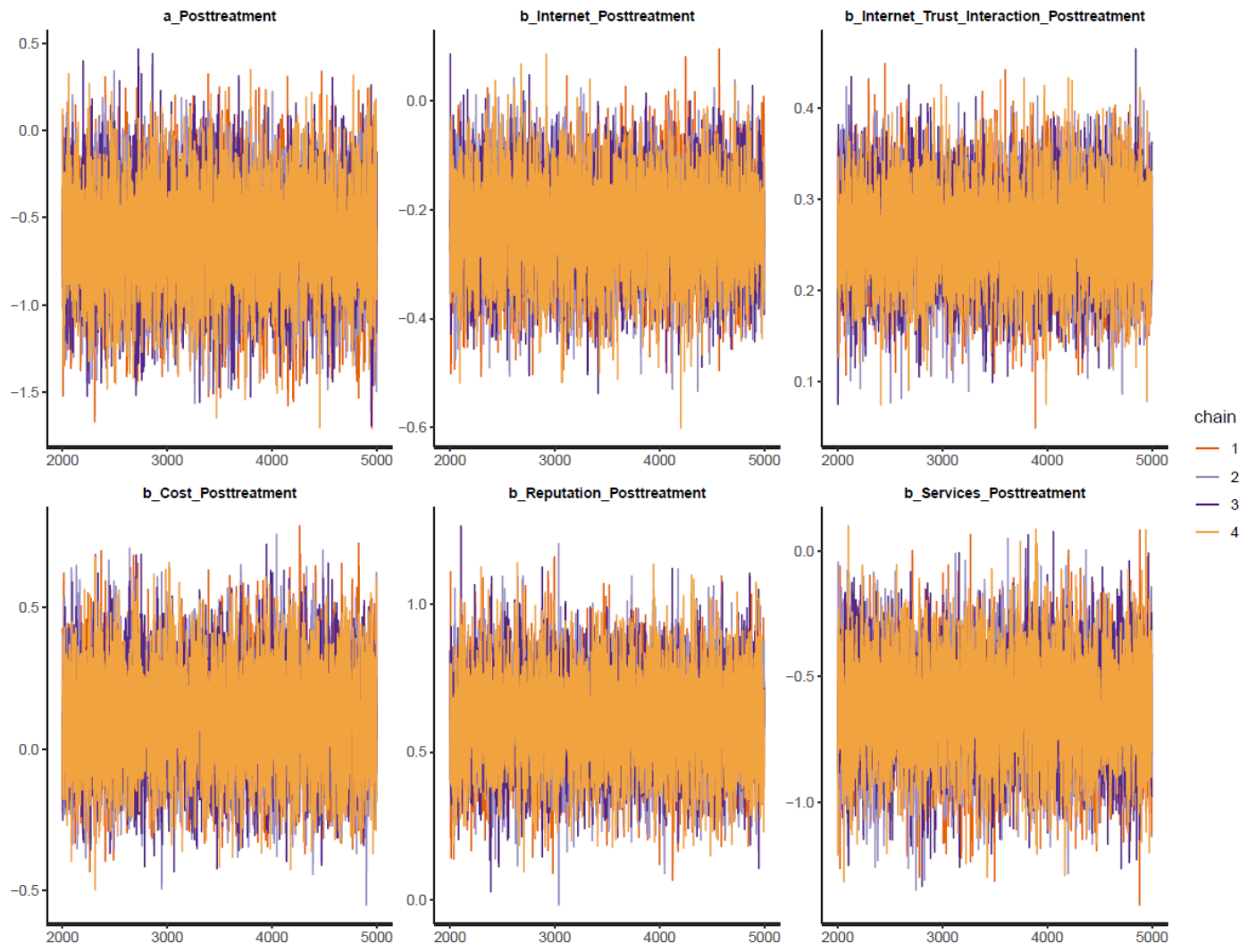
Figure 11: Model 3's trace plots

Table 4: Model 3's simulated posteriors

\begin{tabular}{|c|c|c|c|c|c|c|c|c|}
\hline \multirow{2}{*}{ Parameters } & \multicolumn{2}{|c|}{$\begin{array}{c}\text { Uninformative } \\
\text { prior }\end{array}$} & $\begin{array}{c}\text { Prior-tweaking } \\
\text { (belief on } \\
\text { effect) }\end{array}$ & $\begin{array}{c}\text { Prior-tweaking } \\
\text { (disbelief on } \\
\text { effect) }\end{array}$ & n_eff* & Rhat* \\
\cline { 2 - 9 } & Mean & SD & Mean & SD & Mean & SD & & \\
\hline Constant & -0.62 & 0.31 & -0.62 & 0.30 & -0.62 & 0.31 & 7402 & 1 \\
\hline Internet & -0.23 & 0.09 & -0.24 & 0.09 & -0.23 & 0.09 & 8652 & 1 \\
\hline Internet*Internet_Trust & 0.26 & 0.05 & 0.27 & 0.05 & 0.25 & 0.05 & 10215 & 1 \\
\hline Cost & 0.11 & 0.18 & 0.11 & 0.18 & 0.11 & 0.18 & 10314 & 1 \\
\hline Reputation & 0.61 & 0.16 & 0.61 & 0.15 & 0.60 & 0.16 & 9452 & 1 \\
\hline Services & -0.63 & 0.20 & -0.63 & 0.20 & -0.63 & 0.20 & 10332 & 1 \\
\hline \multirow{7}{*}{$n$ n_eff and Rhat values presented in the tables are the effective sample sizes and Gelman values } \\
taken from the simulated results using uninformative prior.
\end{tabular}

The simulated results of Internet and Internet*Internet_Trust using Model 3 remain almost similar to the results acquired using Model $2\left(\pi_{\text {Internet }}=-0.23\right.$ and $\sigma_{\text {Internet }}=0.09$; $\pi_{\text {Internet } * \text { Internet_Trust }}=0.26$ and $\left.\sigma_{\text {Internet } * \text { Internet_Trust }}=0.05\right)$. The probability distributions shown in Figure 12 hint at the high reliability of Internet's and Internet*Internet_Trust's impacts on ex-post assessment of healthcare providers. In particular, the 95\% Highest Posterior Distribution Intervals (HPDIs) of Internet and Internet*Internet_Trust are entirely on the negative and positive sides, respectively. Moreover, results obtained after the prior-tweaking show that the model is not sensitive to prior belief modification.

Therefore, it is plausible to conclude that the negative association between Internet and Posttreatment and the positive association between Internet*Internet_Trust and Posttreatment are highly reliable and robust. 

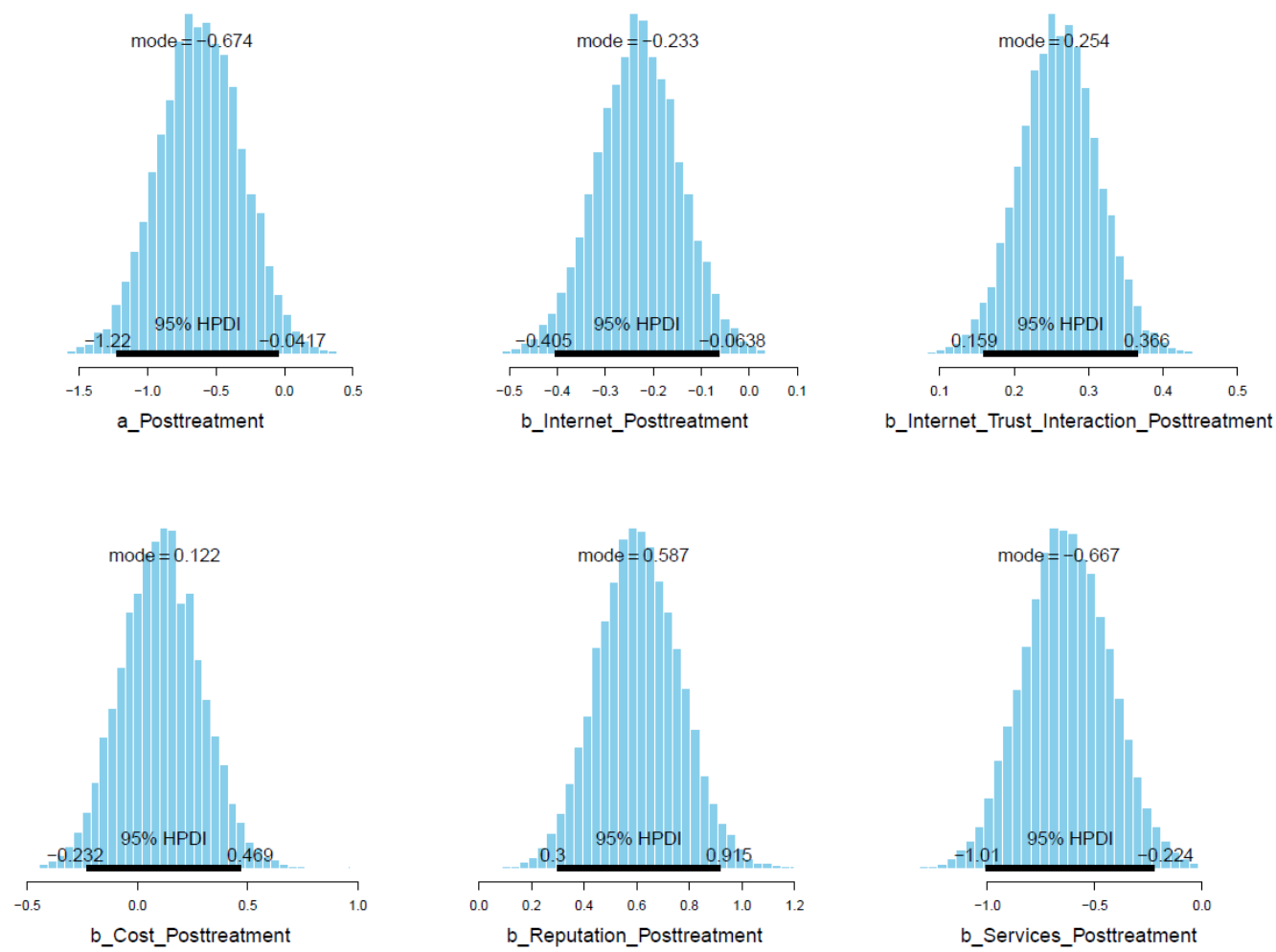

Figure 12: Distributions of Model 3's coefficients with HPDI 95\%

The simulated results also delineate that Cost and Reputation positively influence the ex-post assessment of providers $\left(\pi_{\text {Cost }}=0.11\right.$ and $\sigma_{\text {Cost }}=0.18 ; \pi_{\text {Reputation }}=0.61$ and $\sigma_{\text {Reputation }}=$ 0.16). Nevertheless, while the association between Reputation and Posttreatment is highly reliable because its HPDI is entirely located on the positive side, the association between Cost and Posttreatment only has low confidence because a large proportion of the HDPI still lies on the negative side, and its standard deviation is large. In contrast, Services negatively influences the ex-post assessment $\left(\pi_{\text {Services }}=-0.63\right.$ and $\left.\sigma_{\text {Services }}=0.20\right)$; its negative effect is highly reliable because all the HPDI appears on the negative side.

\section{Discussion}

The current study explored patients' psychological process of Internet information for decision making and ex-post evaluation of their healthcare providers. It is one of the first studies to implement the BMF approach in studying healthcare management. Specifically, the Mindsponge mechanism was capitalized to theoretically construct three models, while Bayesian statistics was performed using a dataset of 1,459 Vietnamese patients to analyze these models.

Model 1's result shows that the information accessibility of Internet sources is positively associated with patients' perceived information sufficiency for choosing a healthcare provider, and trust toward Internet sources facilitates this positive effect. This result is rather straightforward and intuitively expected as it is consistent with former studies on the role of Internet sources of healthcare information (Lemire et al., 2008; Rains, 2007; Sheng \& Simpson, 2015). Focusing more on the effect of trust, we again show how trust functions in terms of 
information processing, which can be considered a "priority pass" within the Mindsponge mechanism. This important aspect of trust, especially regarding evaluating an information source before information reception, was investigated in former studies employing the Mindsponge framework (Nguyen et al., 2021; Vuong et al., 2021b).

However, our findings also show a rather interesting effect: higher accessibility to Internet information predicts negative ex-post evaluation (see results of Model 2 and 3), but this effect is negated by trust toward Internet sources. The ex-post evaluation is made based on comparing previously acquired information (Internet and non-Internet information) and information acquired from real experience (the treatment). The result of Model 1 suggests that the dependence on Internet information in making decisions may increase together with the amount of information acquired from Internet sources, so it is plausible to say that the negative outcome happens when the information acquired from the Internet is not aligned with the patient's real experience. In other words, a patient might be more likely to consider his/her selection of providers based on Internet information as "worse" than (not as "optimal" as) experienced reality or perception about other providers suggested by non-Internet sources. Following the scarcity principle, perceived low-prevalent characteristics are evaluated more extremely (Ditto \& Jemmott, 1989). This means that the perceived high abundance of Internet information may lead to more "moderate" evaluation, in turn leaving more room for yet-to-be-identified better (more "optimal") alternatives. Regardless of the causes, this negative relationship holds the dangerous risk of eroding trust toward Internet sources regarding healthcare information.

Trust towards Internet sources was found to negate the feeling of "bad choice" in patients having gone through treatment. It might result from the fact that trust increases the speed of absorbing information from the Internet, which competes with the amount of information received from non-Internet sources. Furthermore, according to Mindsponge principles, trust is not naturally given but rather the result of the previous evaluation, meaning that those who trust Internet sources have already well-assessed these sources of information. Making a choice is a complex psychological process involving a great deal of information filtering (Vuong \& Napier, 2014). Thus, thanks to the previous evaluation, patients might know better whether the searched information on the Internet is "good" or "bad" and consequently can make more accurate decisions than those with low trust toward their source.

Additionally, information on the Internet often does not accurately reflect reality, like the case of over-promising advertisements, which cause false expectations in consumers. Overall, the dissimilarities between real experience and Internet information might make the patient feel negative about his/her choice. This emphasizes the importance of quality control and public trust-building for Internet-based healthcare information (Jabeen et al., 2018; Lu et al., 2018; Tonsaker et al., 2014).

Regarding how the perception of important factors leading to provider choice influences posttreatment assessment, we found that cost does not have a significant effect. In contrast, professional reputation has a positive effect, and service has a negative effect. These results show that patients who think the professional reputation of the healthcare providers is the decisive factor for their choice will be more likely to assess that their decision has been optimal after the 
treatment. The opposite happens for those who have based their choice more on the provider's services. Considering that Vietnamese tend to have a high level of trust toward a small circle of closely known people (An \& Phuong, 2021), this pattern of social trust increases the perceived value of information from person-to-person communication. As reputation is the socially established general trust toward a healthcare provider (Shore, 2005), people use this when exchanging information, especially in the popular form of personal recommendation. It can also be speculated that such over-reliance on reputation from close-group channels may lead to biased ex-post evaluation (favoring group's assessment over one's assessment). Regarding people who emphasize the importance of healthcare services in their decision, the results might indicate that, regardless of reasons, the services they received tend to be (perceived as) worse than what they had expected. This aspect points to the role of transparency and reliability in providing healthcare information to the public.

Developing and managing a good digital healthcare system is complex (Mathews et al., 2019). In developing a good digital government-based healthcare system in Vietnam, trust and transparency are among the crucial factors (Nguyen et al., 2020). Indeed, effective communication through Internet channels requires public trust. Suppose we solely focus on improving information availability in technical aspects (e.g., infrastructure and technology) without paying enough attention to social aspects, particularly the trust factor. In that case, the system will hold the risk of not being used effectively no matter how accessible it may become. Trust-building is timely and requires a systematic approach. The Mindsponge mechanism suggests that human has an updating manner, meaning that the evaluation of new information will be based on previous evaluations, creating reinforcing loops. Thus, trust must be built stepby-step, and bad implementations causing serious public distrust would not only disrupt and reset the effort. Still, they may also reignite and reinforce former negative attitudes.

As our findings highlight the importance of trust and the adverse effects of flooding information on the Internet, an Internet information monitoring framework should be designed and implemented to improve communication effectiveness and eventually facilitate the adoption of the digital health system. Capitalizing on the positive effect of professional reputation on patients' perceptions, reputational healthcare providers should develop appropriate online resources for patients and promote open discussion between doctors and patients about online health information (Tonsaker et al., 2014).

The current study's limitations are presented and discussed for transparency (Vuong, 2020). The data we use for analysis was collected during 2015-2016. The general public during the COVID19 pandemic may exhibit some differences in their attitudes toward the healthcare system. Additionally, a 5-year period in our world of rapidly advancing technology can cause significant changes regarding the technical capacity of the digital healthcare system. However, collecting new data using the same methodology during this crisis would face numerous obstacles due to social distancing policies. Our theoretical design and methodology are based on a framework of information processing mechanism (Mindsponge mechanism), so they can be easily replicated using new data. Our data were collected in Northern Vietnam, so the founded effects might, to some extent, be influenced by the socio-cultural differences among regions. Nevertheless, the 
findings can still be representative for Vietnamese patients because the regional distinctions are not significant.

\section{Supplementary}
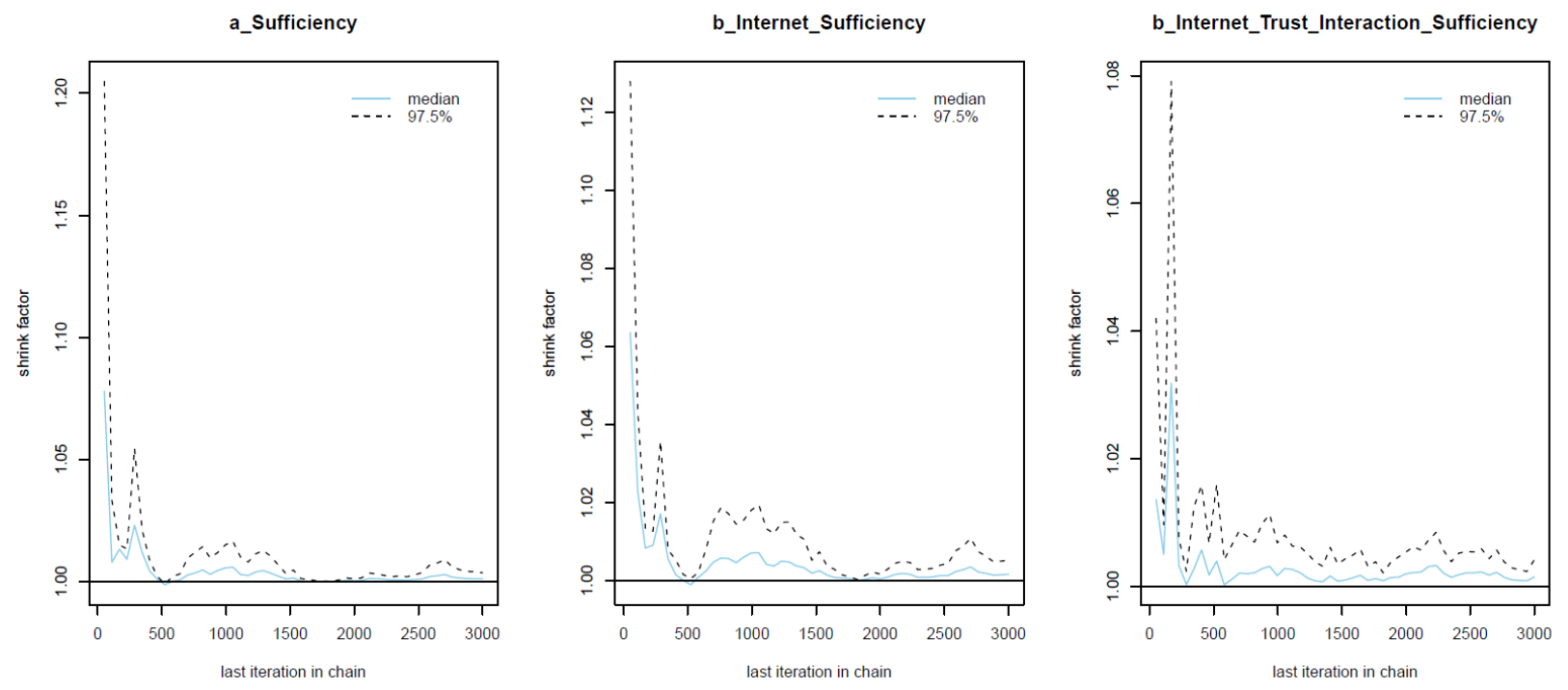

Figure S1: Model 1's Gelman plots
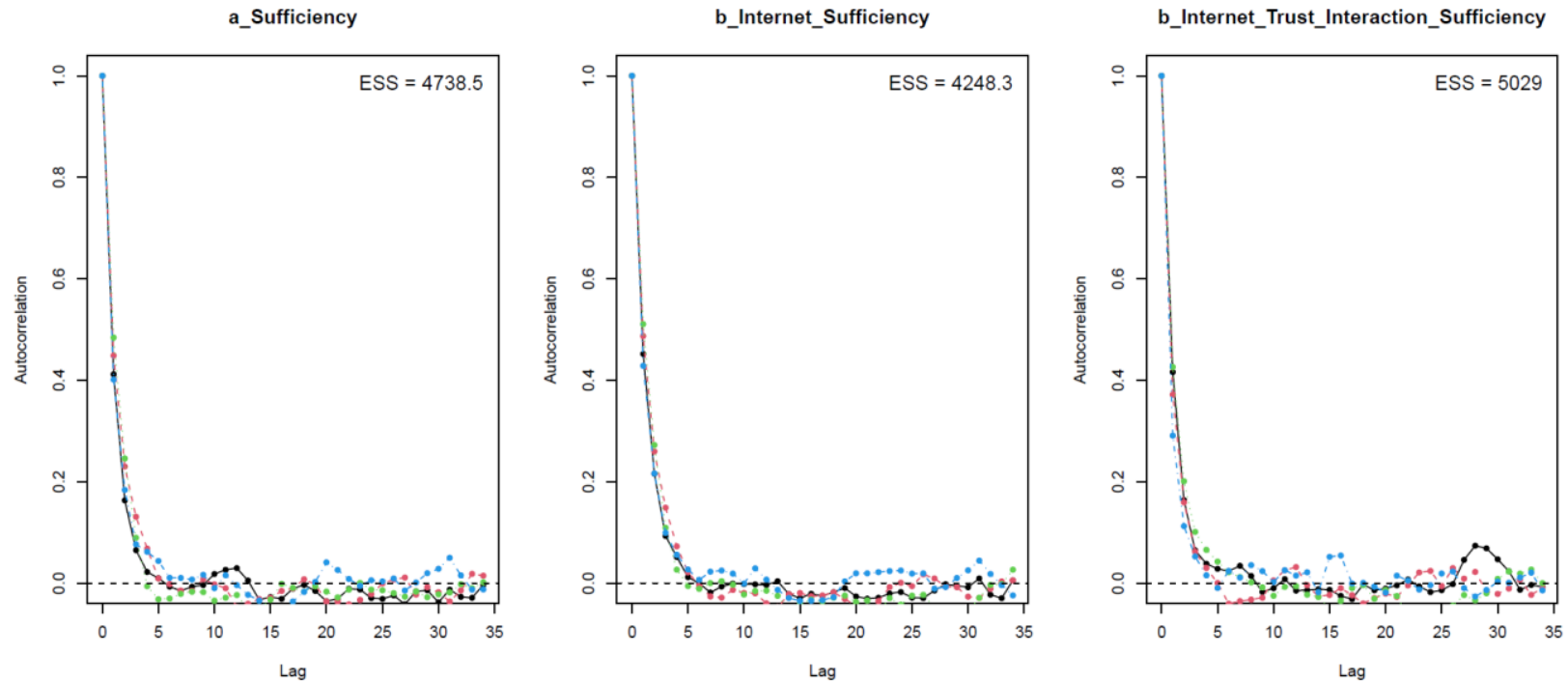

Figure S2: Model 1's autocorrelation plots 

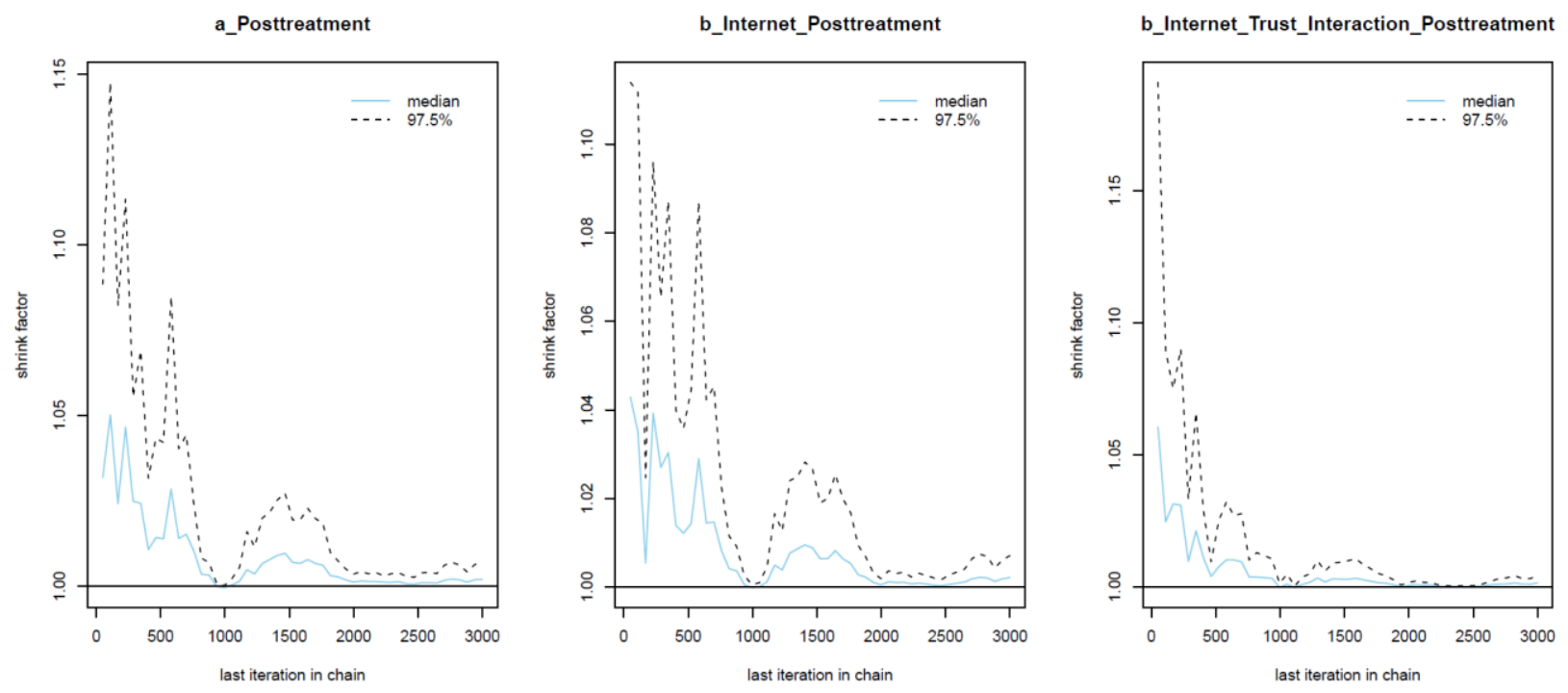

Figure S3: Model 2's Gelman plots
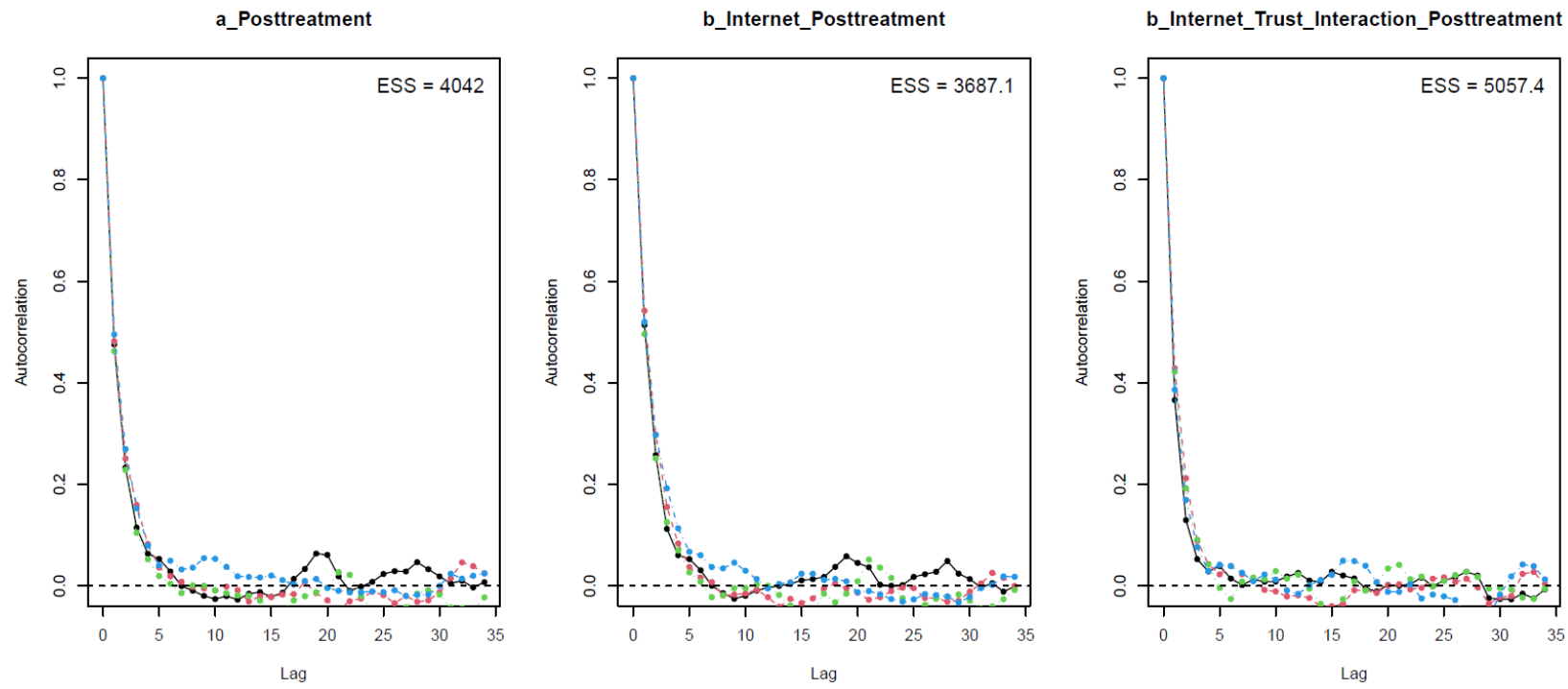

Figure S4: Model 2's autocorrelation plots 

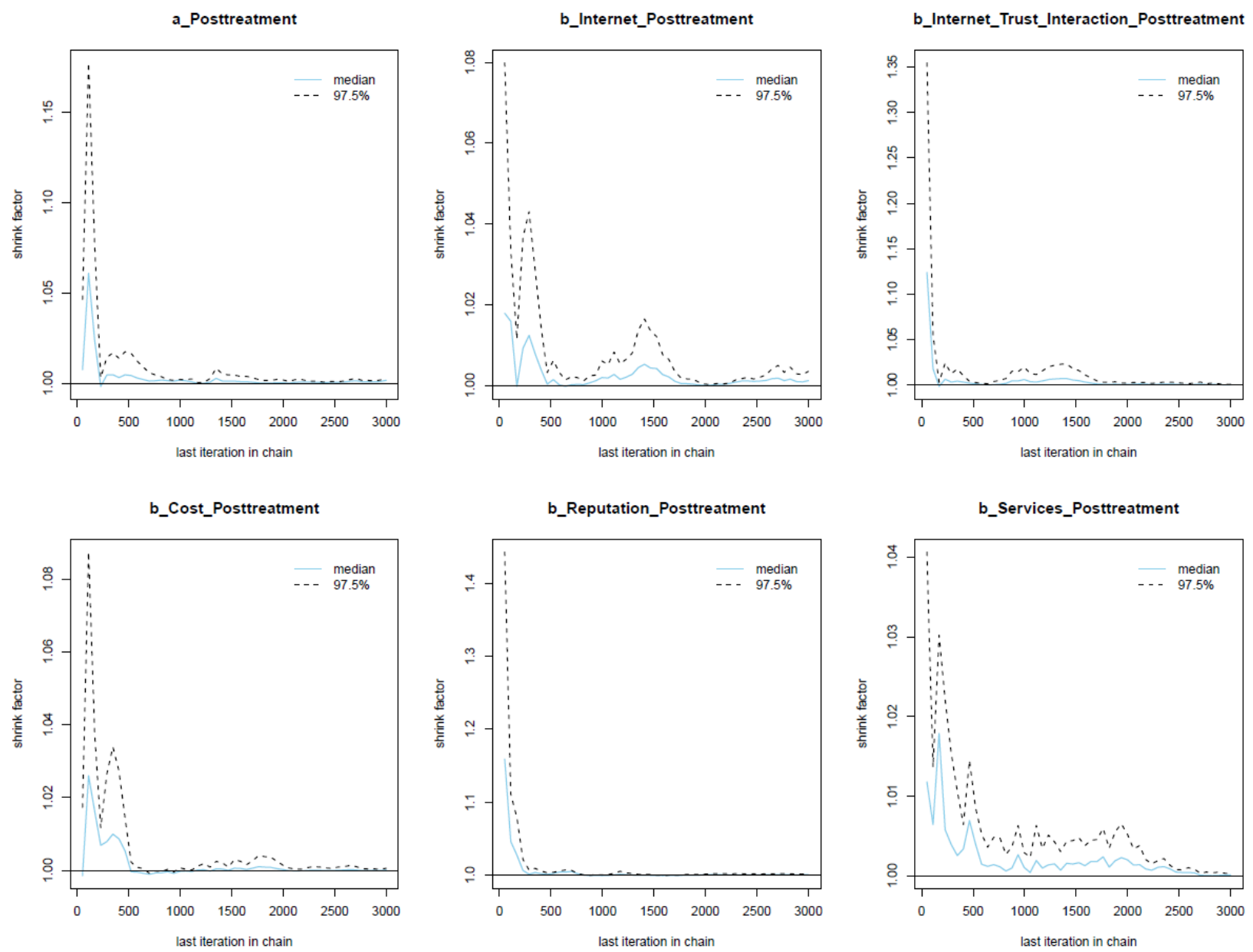

Figure S5: Model 3's Gelman plots 

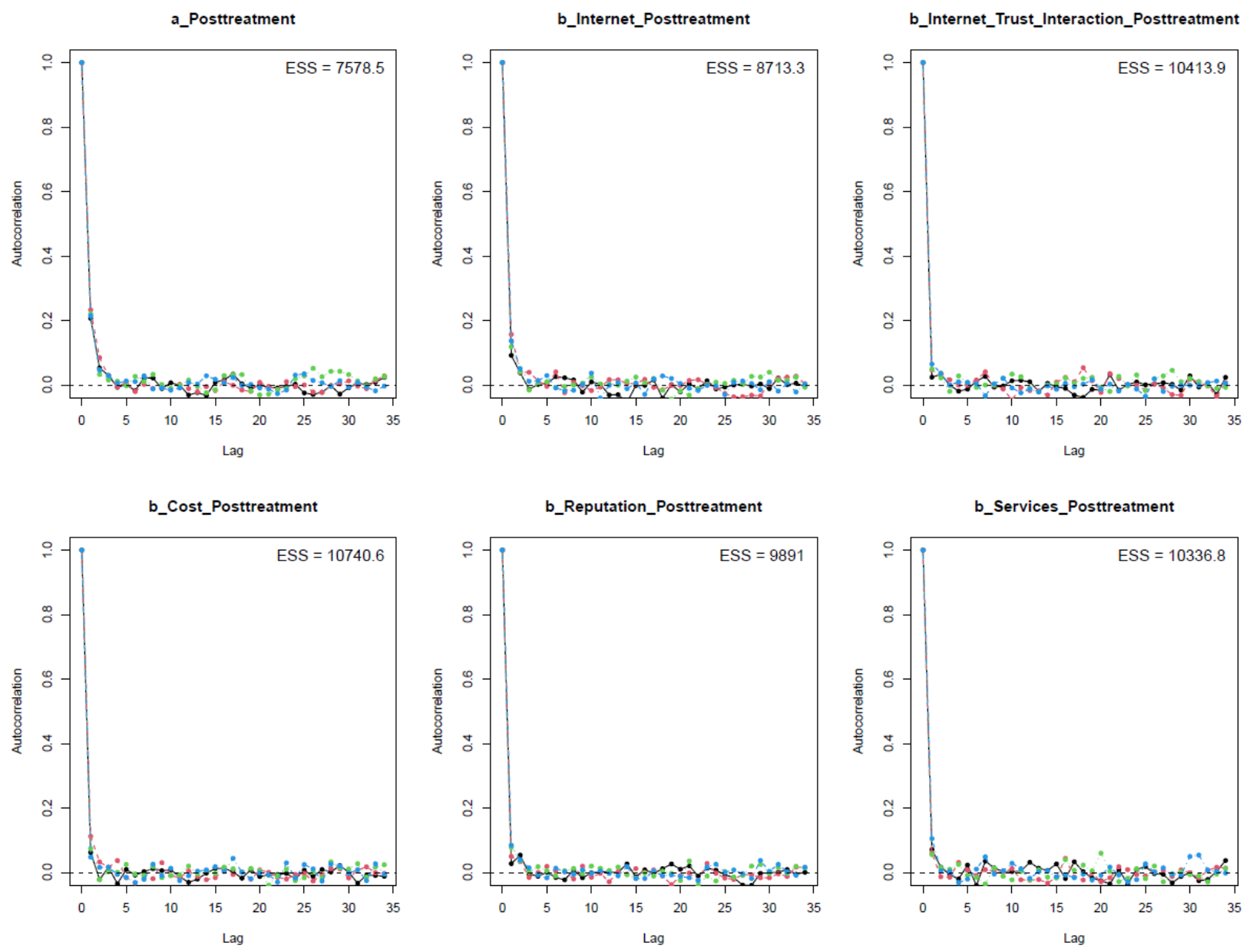

Figure S6: Model 3's autocorrelation plots

\section{References}

An, N. H., \& Phuong, L. D. M. (2021). Social Capital in Vietnam: An Analysis of Social Networks and Social Trust. Journal of Mekong Societies, 17(2), 1-27. https://so03.tcithaijo.org/index.php/mekongjournal/article/view/249714

Baker, M. (2015). Over half of psychology studies fail reproducibility test. Nature. https://doi.org/https://doi.org/10.1038/nature.2015.18248

Bui, L., Ha, S., Nguyen, H., Nguyen, T. T., Nguyen, T., Tran, K., . . . Pham, N. (2021). The contribution of digital health in the response to COVID-19 in Vietnam. Frontiers in public health, 9, 1-6.

Cable.co.uk. (2004). Worldwide mobile data pricing 2021. https://www.cable.co.uk/mobiles/worldwide-data-pricing/

Chowdhury, R., Luhar, S., Khan, N., Choudhury, S. R., Matin, I., \& Franco, O. H. (2020). Longterm strategies to control COVID-19 in low and middle-income countries: an options overview of community-based, non-pharmacological interventions. European Journal of Epidemiology, 35(8), 743-748. 
Csilléry, K., Blum, M. G., Gaggiotti, O. E., \& François, O. (2010). Approximate Bayesian computation (ABC) in practice. Trends in Ecology and Evolution, 25(7), 410-418. https://doi.org/10.1016/j.tree.2010.04.001

Cummins, N., \& Schuller, B. W. (2020). Five crucial challenges in digital health. Frontiers in Digital Health, 2, 38.

Dickerson, S. S., Reinhart, A., Boemhke, M., \& Akhu-Zaheya, L. (2011). Cancer as a problem to be solved: internet use and provider communication by men with cancer. CIN: Computers, Informatics, Nursing, 29(7), 388-395.

Ditto, P. H., \& Jemmott, J. B. (1989). From rarity to evaluative extremity: Effects of prevalence information on evaluations of positive and negative characteristics. Journal of Personality and Social Psychology, 57(1), 16-26. https://doi.org/10.1037/00223514.57.1.16

Frank, S. R. (2000). Digital health care - the convergence of health care and the Internet. The Journal of Ambulatory Care Management, 23(2), 8-17.

Galarce, E. M., Ramanadhan, S., \& Viswanath, K. (2011). Health information seeking. In T. Thompson, R. Parrott, \& J. Nussbaum (Eds.), The Routledge handbook of health communication (pp. 194-207). Routledge.

Gunasekeran, D. V., Tham, Y.-C., Ting, D. S., Tan, G. S., \& Wong, T. Y. (2021). Digital health during COVID-19: lessons from operationalising new models of care in ophthalmology. The Lancet Digital Health, 3(2), e124-e134.

Harris, K., Buntin, M., \& The RAND Corporation. (2008). Choosing a health care provider: the role of quality information (The Synthesis Report: New Insights from Research Results, Issue. R. W. J. Foundation. https://www.issuelab.org/resources/6228/6228.pdf

Hong, T. (2008). Internet health information in the patient-provider dialogue. CyberPsychology and Behavior, 11(5), 587-589.

Jabeen, F., Hamid, Z., Akhunzada, A., Abdul, W., \& Ghouzali, S. (2018). Trust and Reputation Management in Healthcare Systems: Taxonomy, Requirements and Open Issues. IEEE Access, 6, 17246-17263. https://doi.org/10.1109/ACCESS.2018.2810337

Kerkhoff, D., \& Nussbeck, F. W. (2019). The influence of sample size on parameter estimates in three-level random-effects models. Frontiers in Psychology, 10, 1067. https://doi.org/10.3389/fpsyg.2019.01067

Lemire, M., Paré, G., Sicotte, C., \& Harvey, C. (2008). Determinants of Internet use as a preferred source of information on personal health. International Journal of Medical Informatics, 77(11), 723-734.

Lennon, M. R., Bouamrane, M.-M., Devlin, A. M., O'connor, S., O'donnell, C., Chetty, U., . . . Finch, T. (2017). Readiness for delivering digital health at scale: lessons from a longitudinal qualitative evaluation of a national digital health innovation program in the United Kingdom. Journal of Medical Internet Research, 19(2), e6900.

Lu, X., Zhang, R., Wu, W., Shang, X., \& Liu, M. (2018). Relationship between internet health information and patient compliance based on trust: empirical study. Journal of Medical Internet Research, 20(8), e253.

Mathews, S. C., McShea, M. J., Hanley, C. L., Ravitz, A., Labrique, A. B., \& Cohen, A. B. (2019). Digital health: a path to validation. NPJ Digital Medicine, 2(1), 1-9.

McKinley, C. J., \& Wright, P. J. (2014). Informational social support and online health information seeking: Examining the association between factors contributing to healthy eating behavior. Computers in Human Behavior, 37, 107-116. 
Mitgang, E. A., Blaya, J. A., \& Chopra, M. (2021). Digital Health in Response to COVID-19 in Low-and Middle-income Countries: Opportunities and Challenges. Global Policy.

Nguyen, M.-H., \& Le, T.-T. (2021). Bayesian Mindsponge Framework. In Scholarly Community Encyclopedia. Basel, Switzerland: MDPI AG.

Nguyen, M.-H., Le, T.-T., Nguyen, H.-K. T., Ho, M.-T., Nguyen, H. T. T., \& Vuong, Q.-H. (2021). Alice in Suicideland: Exploring the Suicidal Ideation Mechanism through the Sense of Connectedness and Help-Seeking Behaviors. International Journal of Environmental Research and Public Health, 18(7), 3681. https://doi.org/10.3390/ijerph18073681

Nguyen, T. T., Phan, D. M., Le, A. H., \& Nguyen, L. T. N. (2020). The Determinants of Citizens' Satisfaction of E-Government: An Empirical Study in Vietnam. The Journal of Asian Finance, Economics and Business, 7(8), 519-531. https://doi.org/10.13106/jafeb.2020.vol7.no8.519

Open Science Collaboration. (2015). Estimating the reproducibility of psychological science. science, 349(6251). https://doi.org/10.1126/science.aac4716

Rains, S. A. (2007). Perceptions of traditional information sources and use of the world wide web to seek health information: findings from the health information national trends survey. Journal of Health Communication, 12(7), 667-680.

Ritchie, H., Mathieu, E., Rodés-Guirao, L., Appel, C., Giattino, C., Ortiz-Ospina, E., . . Roser, M. (2020). Coronavirus Pandemic (COVID-19). https://ourworldindata.org/coronavirus

Serbanati, L. D., Ricci, F. L., Mercurio, G., \& Vasilateanu, A. (2011). Steps towards a digital health ecosystem. Journal of Biomedical Informatics, 44(4), 621-636.

Sheng, X., \& Simpson, P. M. (2015). Health care information seeking and seniors: determinants of Internet use. Health Marketing Quarterly, 32(1), 96-112.

Shore, D. A. (2005). The trust prescription for healthcare: building your reputation with consumers. Health Administration Press.

The World Bank. (2020). Individuals using the Internet (\% of population) - Vietnam. https://data.worldbank.org/indicator/IT.NET.USER.ZS?locations=VN

Thompson, N. M., Bevan, J. L., \& Sparks, L. (2012). Healthcare reform information-seeking: Relationships with uncertainty, uncertainty discrepancy, and health self-efficacy. Journal of Communication in Healthcare, 5(1), 56-66.

Tonsaker, T., Bartlett, G., \& Trpkov, C. (2014). Health information on the Internet: gold mine or minefield? Canadian Family Physician, 60(5), 407-408.

Tu, H. T., \& Lauer, J. R. (2008). Word of mouth and physician referrals still drive health care $\begin{array}{lllll}\text { provider } & \text { choice. } & \text { Research } & \text { Brief, } & 9,\end{array}$ https://www.issuelab.org/resources/11695/11695.pdf

Vehtari, A., Gelman, A., \& Gabry, J. (2017). Practical Bayesian model evaluation using leaveone-out cross-validation and WAIC. Statistics and computing, 27(5), 1413-1432. https://doi.org/10.1007/s11222-016-9696-4

Vuong, Q.-H. (2020). Reform retractions to make them more transparent. Nature, 582(7811), 149. https://doi.org/10.1038/d41586-020-01694-X

Vuong, Q.-H., La, V.-P., Nguyen, M.-H., Ho, M.-T., Tran, T., \& Ho, M.-T. (2020). Bayesian analysis for social data: A step-by-step protocol and interpretation. MethodsX, 7, 100924. https://doi.org/10.1016/j.mex.2020.100924

Vuong, Q.-H., \& Napier, N. K. (2015). Acculturation and global mindsponge: an emerging market perspective. International Journal of Intercultural Relations, 49, 354-367. 
Vuong, Q.-H., Nguyen, M.-H., \& Le, T.-T. (2021a). Home scholarly culture, book selection reason, and academic performance: Pathways to book reading interest among secondary school students. European Journal of Investigation in Health, Psychology and Education, 11(2), 468-495. https://doi.org/https://doi.org/10.3390/ejihpe11020034

Vuong, Q.-H., Nguyen, M.-H., \& Le, T.-T. (2021b). A mindsponge-based investigation into the psycho-religious mechanism behind suicide attacks. De Gruyter / Sciendo.

Vuong, Q. H., \& Napier, N. K. (2014). Making creativity: the value of multiple filters in the innovation process. International Journal of Transitions and Innovation Systems, 3(4), 294-327. https://doi.org/10.1504/IJTIS.2014.068306

Vuong, Q. H., \& Napier, N. K. (2015). Acculturation and global mindsponge: An emerging market perspective. International Journal of Intercultural Relations, 49, 354-367. https://doi.org/10.1016/i.ijintrel.2015.06.003

Walker, P. G., Whittaker, C., Watson, O. J., Baguelin, M., Winskill, P., Hamlet, A., . . . Green, W. (2020). The impact of COVID-19 and strategies for mitigation and suppression in low-and middle-income countries. science, 369(6502), 413-422. 